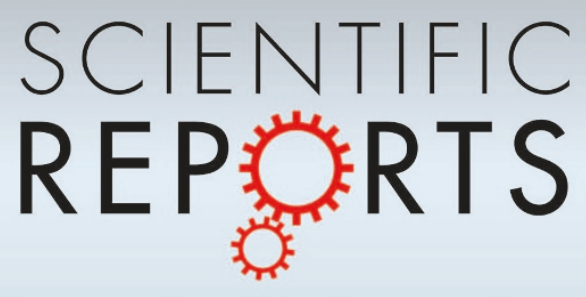

OPEN

SUBJECT AREAS:

SYNTHESIS AND

PROCESSING

ELECTRONIC PROPERTIES AND

DEVICES

Received

24 September 2014

Accepted

5 December 2014

Published

8 January 2015

Correspondence and requests for materials should be addressed to R.Z. (renyun.zhang@ miun.se)

\section{Thermally reduced kaolin-graphene oxide nanocomposites for gas sensing}

Renyun Zhang, Viviane Alecrim, Magnus Hummelgård, Britta Andres, Sven Forsberg, Mattias Andersson \& Håkan Olin

Department of Natural Sciences, Mid Sweden University, SE-85170 Sundsvall, Sweden.

Highly sensitive graphene-based gas sensors can be made using large-area single layer graphene, but the cost of large-area pure graphene is high, making the simpler reduced graphene oxide ( $\mathrm{rGO}$ ) an attractive alternative. To use rGO for gas sensing, however, require a high active surface area and slightly different approach is needed. Here, we report on a simple method to produce kaolin-graphene oxide (GO) nanocomposites and an application of this nanocomposite as a gas sensor. The nanocomposite was made by binding the GO flakes to kaolin with the help of 3-Aminopropyltriethoxysilane (APTES). The GO flakes in the nanocomposite were contacting neighboring GO flakes as observed by electron microscopy. After thermal annealing, the nanocomposite become conductive as showed by sheet resistance measurements. Based on the conductance changes of the nanocomposite films, electrical gas sensing devices were made for detecting $\mathrm{NH}_{3}$ and $\mathrm{HNO}_{3}$. These devices had a higher sensitivity than thermally annealed multilayer GO films. This kaolin-GO nanocomposite might be useful in applications that require a low-cost material with large conductive surface area including the demonstrated gas sensors.

G raphene has gained attention during the past few years ${ }^{1}$, stimulating research in several fields, including electronics ${ }^{2}$, nanomedicine ${ }^{3}$, and spectroscopy ${ }^{4}$. Recently, graphene based gas sensing has been demonstrated $^{5}$, utilizing the high conductivity of graphene as well as the high sensitivity to surface dopants due to the two-dimensionality of the atomically thin material ${ }^{6}$. The adsorbed gas molecules on graphene act as electron donors or acceptors, changing the charge carrier concentration and thus altering the resistivity of graphene $e^{6}$. This has allowed the demonstration of highly sensitive graphene-based gas sensor with a detection limit down to individual molecules ${ }^{5}$. To make such graphene-based gas sensors, large area pure graphene (synthesized or physically separated from graphite) is needed.

However, the cost of large-area pure graphene is high. Instead, one can oxidize graphite to graphene oxide $(\mathrm{GO})^{7}$ and then, to increase the conductivity, reduce it by thermal ${ }^{8}$ or chemical ${ }^{9}$ processes to obtain reduced graphene oxide (rGO). Still, the requirement of single-layered films to get enough sensitivity makes route problematic. Multi-layered rGO will be less sensitive since the rGO sheets will bind to each other strongly ${ }^{10}$ hindering the gas to reach the surfaces of all the sheets except the top-most ones. Thus, there is a need to separate the sheets to let the gas reach the graphene surfaces and this may be done by modify the graphene with molecules or particles. Such graphene-based composites have useful electronic properties ${ }^{11}$ and have been applied in several areas, including energy storage by using metal oxide-graphene composites ${ }^{12-15}$ and for biosensors utilizing polymer-graphene composite $e^{16,17}$.

Clay-graphene composites were recently demonstrated ${ }^{18,19}$. This kind of graphene composite might be useful in gas sensing applications since clay is also a two-dimensional material; the clay will separate the graphene sheets and also avoid curling of GO during thermal reduction. However, the studies of the electrical properties of these kinds of 2D-2D composites or their potential applications are limited ${ }^{20}$.

We report here a simple one-step method to produce kaolin-GO nanocomposites using APTES as linkage. The weight fractions of GO in the nanocomposites were between $17 \%$ and $25 \%$. These synthesized nanocomposites were characterized by transmission electron microscopy (TEM), Fourier transform infrared spectroscopy (FTIR) and differential scanning calorimetry (DSC). Electrical properties of these nanocomposites after thermal annealing at different temperatures were determined. Moreover, we studied the potential of these kaolin-GO nanocomposites as gas sensing materials and our results show that these nanocomposites have larger resistance change upon contact with $\mathrm{NH}_{3}$ and $\mathrm{HNO}_{3}$ gas. Thermally annealed kaolin-GO nanocomposites showed a higher sensitivity to these two kinds of gases as compared to thermally annealed GO. This was due to the porous 
structure of the kaolin-GO nanocomposites but might also be assisted by the hydrophilic properties of kaolin. The results suggested that kaolin-GO nanocomposites are useful in gas sensing applications.

\section{Results and Discussion}

Synthesis. Kaolin is a kind of clay, which can interact with molecules that contain silane groups, e.g. APTES can be immobilized on kaolin through the interaction of the silane on APTES with the -OH groups on the kaolin surface ${ }^{21}$. In our experiments, kaolin powder was first treated with high power sonication to separate the flakes, following by adding APTES while stirring. After that, GO was added and stirring was done at $800 \mathrm{rpm}$ for $10 \mathrm{~min}$, following by $300 \mathrm{rpm}$ stirring for $10 \mathrm{~min}$. The color of kaolin changed from white to brown after the binding of GO.

Characterizations. Fig. 1a shows a TEM image of synthesized kaolin-GO nanocomposite, which indicated that GO sheets was immobilized on kaolin flatly without obvious curls on their edges. The image shows that the larger GO sheets were supported by several smaller kaolin flakes. Images at higher and lower magnification are shown in supporting information (Fig. S1 and S2). Fig. 1b shows a SEM image of the nanocomposites, showing the contact of GO sheet with each other over different kaolin flakes. The specific surface area was measured as $28.3 \mathrm{~m}^{2} / \mathrm{g}$ for the nanocomposite used for gas sensing test.
Moreover, the nanocomposite materials show high binding affinity to each other, which was considered due to the contribution of flatness of GO sheets, because the flattened GO sheets can easily interact with each other through van der Waals force and hydrogen bonds of the oxygenated groups. As an indirect indication, Fig. 1c shows two photographs of "donuts" and "spaghetti" made of kaolinGO nanocomposites by dropping or injecting the concentrated nanocomposite suspension into water (more images are shown in Supporting information, Fig. S3). The "donut" and "spaghetti" structure remained stable, demonstrating the internal interaction of the kaolin-GO nanocomposite.

Fig. 1d shows the FTIR of kaolin, GO, and kaolin-GO nanocomposite before and after annealing at $230^{\circ} \mathrm{C}$. The FTIR measurements showed that the $\mathrm{C}=\mathrm{O}$ stretching of $\mathrm{GO}$ shifted from $1713 \mathrm{~cm}^{-1}$ to $1732 \mathrm{~cm}^{-1}$ when kaolin was bonded to GO with APTES as linkage, which might be due to the interaction of $-\mathrm{COOH}$ and $-\mathrm{OH}$ on $\mathrm{GO}$ with $-\mathrm{NH}_{2}$ on APTES through hydrogen bonds. The stretching of $\mathrm{C}=\mathrm{O}$ shifted further to $1746 \mathrm{~cm}^{-1}$ after annealing at $230^{\circ} \mathrm{C}$, which was due to decarboxylation of the $\mathrm{GO}$ sheets. The $\mathrm{C}=\mathrm{C}$ stretching of as synthesized kaolin-GO at $1620 \mathrm{~cm}^{-1}$ did not shift until annealing, when it shifted to $1575 \mathrm{~cm}^{-1}$. This band shift was also due to the removal of $-\mathrm{OH}$, and -O- from the GO plane ${ }^{22}$. Our DSC measurement demonstrated that around $205^{\circ} \mathrm{C}$ there was a decarboxylation process (Fig. 1e), which is consistent with the FTIR results. For X-ray
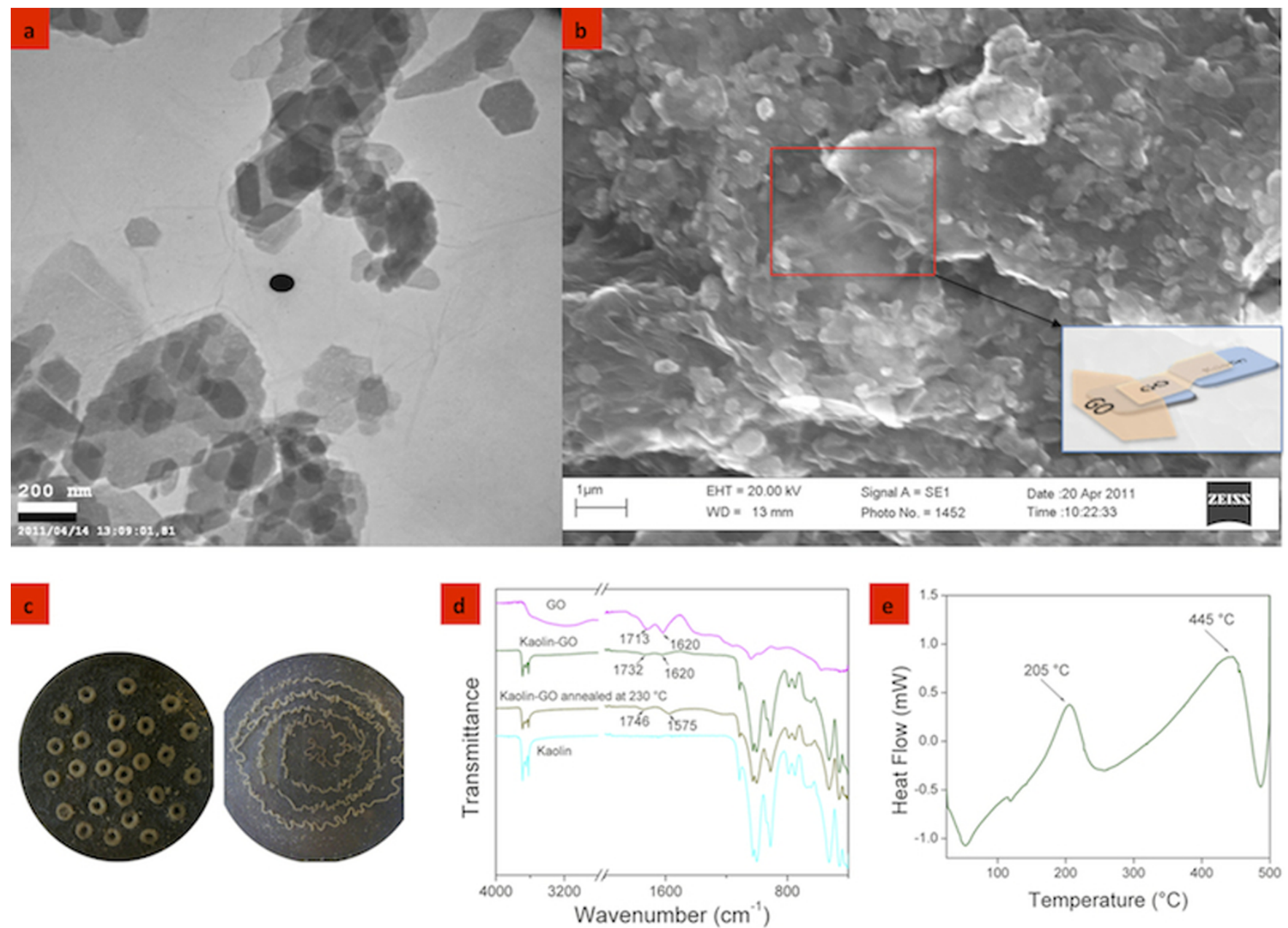

Figure 1 Characterization of kaolin-GO nanocomposites. (a) TEM image of kaolin-GO nanocomposites, showing binding of a GO sheet on multiple kaolin flakes. (b) SEM image of kaolin-GO nanocomposites. The inset is a schematic drawing of the contact between GO sheets in the red frame.

(c) Photographs of "donut" and "spaghetti" made of kaolin-GO nanocomposites. The diameter of the beaker was $6 \mathrm{~cm}$. (d) FTIR of kaolin, GO, kaolinGO before and after annealing at $230^{\circ} \mathrm{C}$. (e) DSC of kaolin-GO measured in air. 
diffraction of kaolin-GO nanocomposites see supporting information (Figure S4).

We further studied the electrical properties of the kaolin-GO nanocomposites. Our microscopy results showed that the GO sheets in the nanocomposites were contacting each other over different kaolin flakes, providing an electrical percolation path through the nanocomposite after annealing. The percolation conductivity of these kind of nanocomposites are determined by the amount of conducting particles ${ }^{11}$, which in our case is the annealed GO sheets. We studied the resistance of kaolin-GO nanocomposites with different GO fractions after annealing at $230^{\circ} \mathrm{C}$, as shown in Fig. 2a. The sheet resistance $\left(\mathrm{R}_{\mathrm{s}}\right)$ of kaolin-GO film decreased from $420 \mathrm{M} \Omega / \mathrm{sq}$ to $35 \mathrm{~K} \Omega / \mathrm{sq}$ when the weight fraction of GO increased from $17 \%$ to $25 \%$, with a sharp decrease in resistance during the lower fraction values, which is consistent with a percolation phenomena. Fig. $2 b$ shows the $\mathrm{R}_{\mathrm{s}}$ of kaolin-GO film at different annealing temperature with GO fraction of $25 \%$. The $\mathrm{R}_{\mathrm{s}}$ went down from $35 \mathrm{~K} \Omega / \mathrm{sq}$ to 400 $\Omega /$ sq when the annealing temperature increased from $230^{\circ} \mathrm{C}$ to $950^{\circ} \mathrm{C}$, showing that conductive kaolin-GO nanocomposite films can be created by annealing. Fig. 2c shows the current-voltage (IV) measurements of kaolin-GO films after annealing at different temperatures, with increasing conductivity at higher annealing temper-
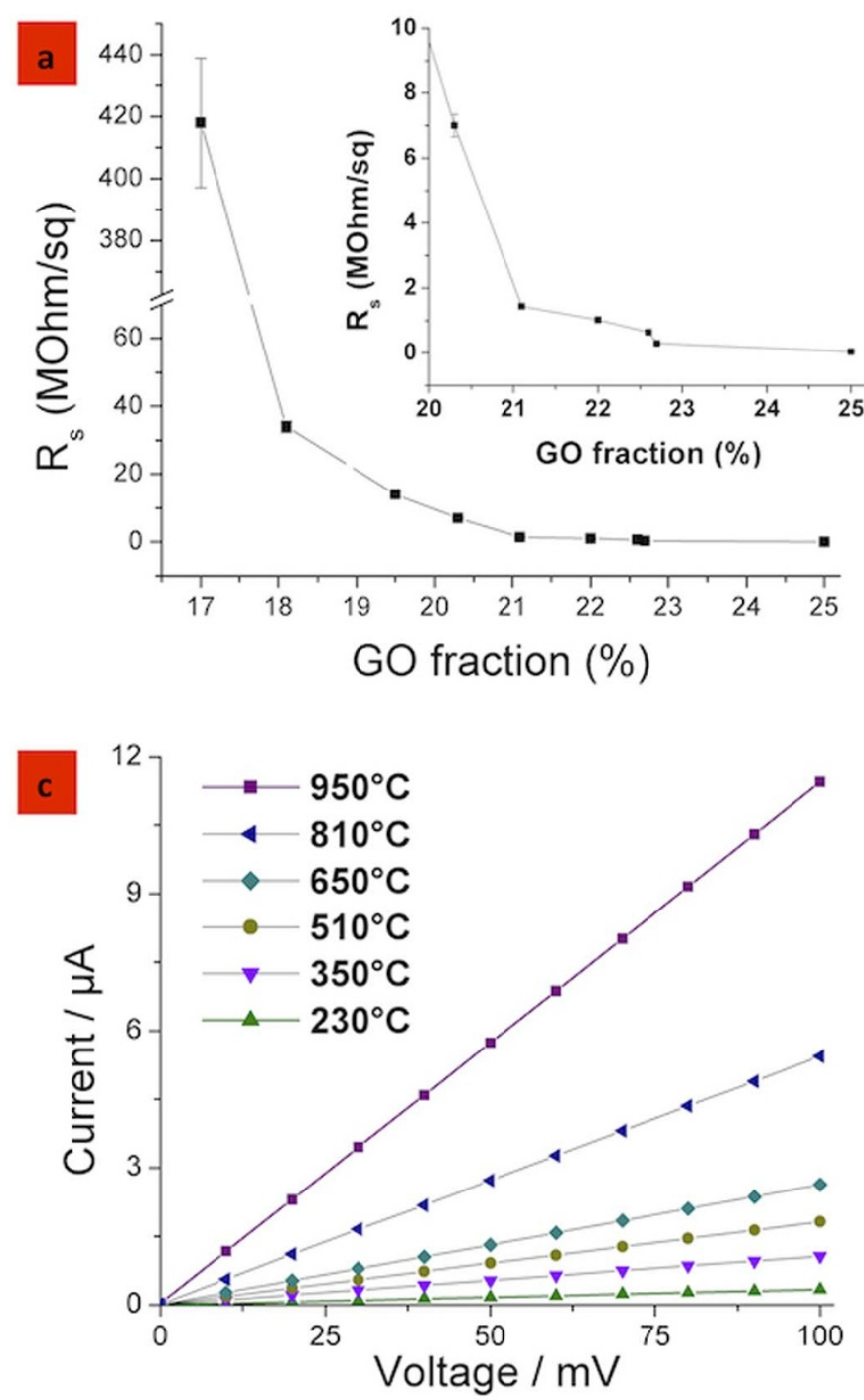

ature. The linear IV curves indicate an Ohmic contact ${ }^{23}$ between the nanocomposite and the stainless wire electrodes used in the measurements. Real time monitoring of the resistance change during the annealing process is illustrated in Fig. 2d. Decarboxylation appeared from $205^{\circ} \mathrm{C}$ to $230^{\circ} \mathrm{C}$ during the heating process, showing fluctuating resistance, as can be seen from Fig. $2 \mathrm{~d}$. These results are consistent with the DSC measurements (see Fig. 1e).

Gas sensing. The annealed kaolin-GO nanocomposites were further applied for gas sensing measurements. Fig. 3a shows the resistance changes of $400^{\circ} \mathrm{C}$ and $600^{\circ} \mathrm{C}$ annealed kaolin-GO nanocomposites responding to $\mathrm{NH}_{3}$ gas flow $\left(\mathrm{NH}_{3}\right.$ concentration: $\left.10 \mu \mathrm{M}\right)$. The graphs show how the resistance of the nanocomposite film changed under $\mathrm{NH}_{3}$ gas flow. A memory effect is apparent from the graphs and the resistance increased proportionally during $\mathrm{ON}$ and OFF cycling of the gas flow, with a higher regressing slope with gas $\mathrm{ON}$.

The results can be explained by considering how the resistance changed over time during a single cycle, as shown in Fig. 3b. In the detection curve, there were two different responding behaviors. The rapid response is due to the of gas molecules to the low-energy binding sites, such as the $s p^{2}$ bonded carbon ${ }^{7}$. The slow response is
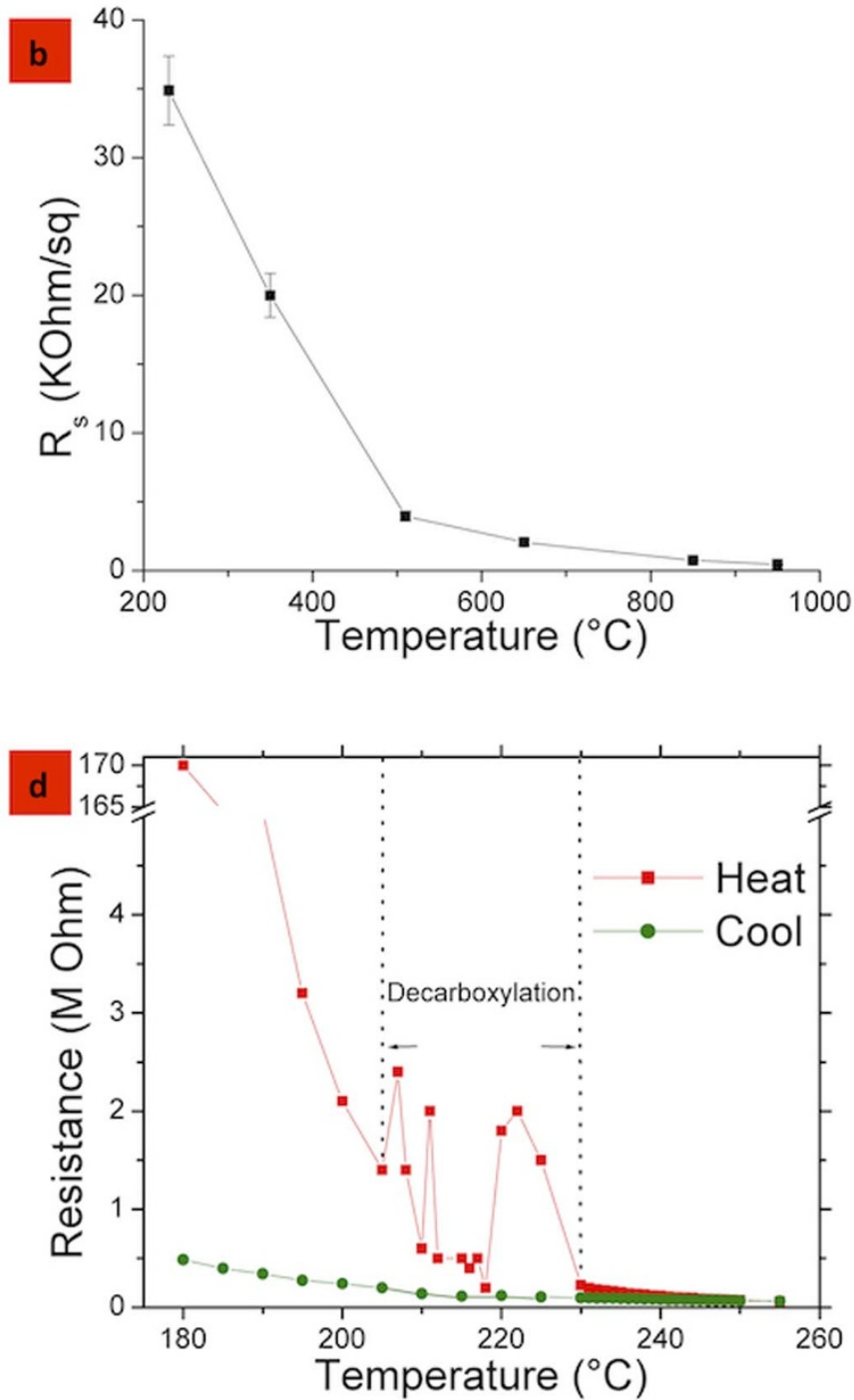

Figure 2 Electrical characterization of kaolin-GO. (a) $\mathrm{R}_{\mathrm{s}}$ of kaolin-GO nanocomposites with different GO fraction in weight \%. (b) $\mathrm{R}_{\mathrm{s}}$ of kaolin-GO nanocomposites (GO fraction: 25\%) annealed at different temperature under the protection of Argon gas. (c) Current-voltage (IV) measurement of kaolin-GO nanocomposites annealed at different temperature under the protection of Argon gas. (d) In-situ measurement of the resistance change of kaolin-GO annealed at $250^{\circ} \mathrm{C}$. The graph shows the resistance from $180^{\circ} \mathrm{C}$ to $250^{\circ} \mathrm{C}$ during heating and cooling. 

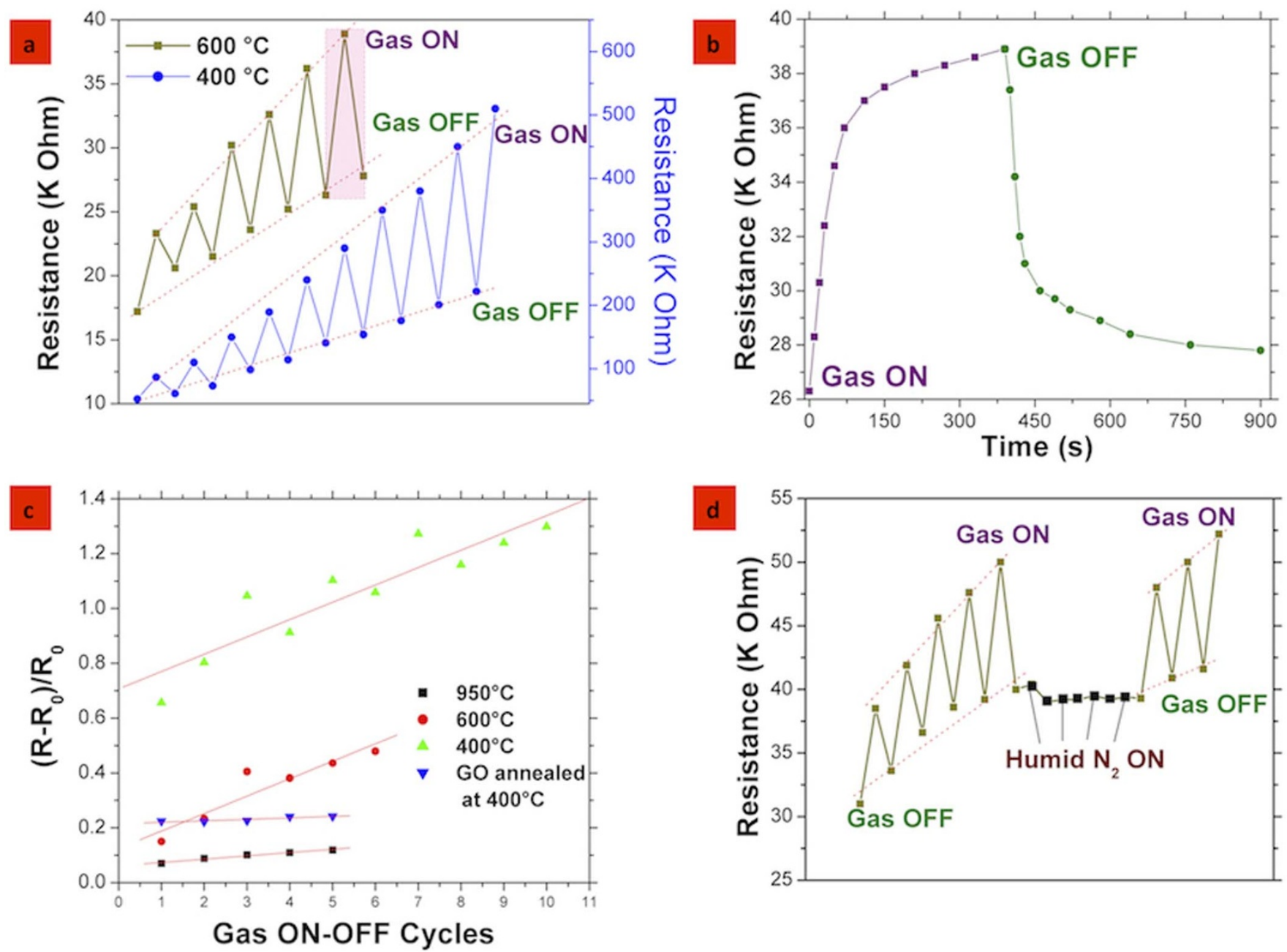

Figure $3 \mid \mathrm{NH}_{3}$ gas sensing using kaolin-GO nanocomposites based sensors. (a) Resistance changes of kaolin-GO films annealed at $400^{\circ} \mathrm{C}$ and $600^{\circ} \mathrm{C}$ upon the blow of $\mathrm{NH}_{3}$ gas. (b) Real-time monitoring of resistance change of $600^{\circ} \mathrm{C}$ annealed kaolin-GO nanocomposites of to the last cycle in a, marked with a light shaded rectangle. (c) Resistance changes of different samples. Here $\mathrm{R}_{0}$ referred to the resistance of the nanocomposites at the beginning of each cycle when gas was OFF. (d) Resistance changes of kaolin-GO films annealed at $600^{\circ} \mathrm{C}$ upon the blow of $\mathrm{NH}_{3}$ gas or humid nitrogen that was blown through double distilled water before reaching the nanocomposite.

due to the binding of gas molecules to the higher-energy binding sites, such as the oxygen functional groups that are highly present in the nanocomposites ${ }^{7}$. When the gas flow was stopped (Fig. 3b), the same kind of rapid-slow response was present making this interpretation consistent. Robinson and co-workers explains that this kind of memory effect is due to the binding energy difference of gas molecules to low and higher-energy binding sites ${ }^{7}$. The binding of gas molecule to $s p^{2}$ bonded carbon is through weak dispersive forces, while the oxygen functional groups have higher binding energy (hundred meV/molecule) ${ }^{24}$. When the gas flow was switched off, the gas molecules at low binding energy sites released very quick, while those bound at high energy sites did not. This model explains why the resistance was not recovered to the original value until several minutes after the gas flow was switched off. Since we run the next cycles without waiting for the resistance to recover totally, we obtained a continuous increasing resistance when gas was switched off.

The sensitivity, as defined by the relative change of resistance ( $R$ $\left.\mathrm{R}_{0}\right) / \mathrm{R}_{0}$ under $\mathrm{NH}_{3}$ gas cycles, is plotted in Fig. $3 \mathrm{c}$ for sensors based on different active materials. The highest sensitivity had the sensors prepared by kaolin-GO nanocomposites annealed at $400^{\circ} \mathrm{C}$ with a resistance change of about $100 \%$ while other sensors had a response below 50\%. For comparison, we also did gas sensing control experiments on thermally reduced GO film without kaolin (thickness:
$100 \mathrm{~nm})$ at $400^{\circ} \mathrm{C}$. The sensitivity of this reduced GO film was about $20 \%$, which is about 5 times lower than the corresponding kaolin-GO nanocomposite, which was expected since the presence of kaolin made an open porous structure, so that a higher surface area of the reduced GO are available to gas molecules.

The increase in sensitivity, as plotted in Fig. 3c, might be due to the hydrophilic property of kaolin. GO, thermally reduced at high temperature, is hydrophobic and does not adsorb water molecules, however, the hydrophilic kaolin will adsorb water. Seredych et al describe two kinds of binding modes of ammonia retention on graphite oxide, where the ammonia molecule can interact with carboxylic groups either as Bronsted or Lewis acids ${ }^{25}$. They point out that the moisture on the graphite oxide surface could enhance the adsorption of ammonia on carboxylic groups. Levesque and co-workers ${ }^{26}$ described the influence of water layers ${ }^{27}$ at the interface between graphene and hydrophilic substrate in graphene transistor applications, where they indicate that humid air shift the $V_{\text {Driac }}$ toward negative $\mathrm{V}_{\mathrm{g}}$.

In our experiments, the adsorbed water molecules will bind more $\mathrm{NH}_{3}$ molecules at the interface between kaolin and GO, increasing the local gas concentration, leading to a high electrical response. This is under the assumption that the water molecules do not influence the resistance. To test this we performed the experiment shown in Fig. 3d with cycles of ammonia gas flow followed by a flow of humid nitro- 


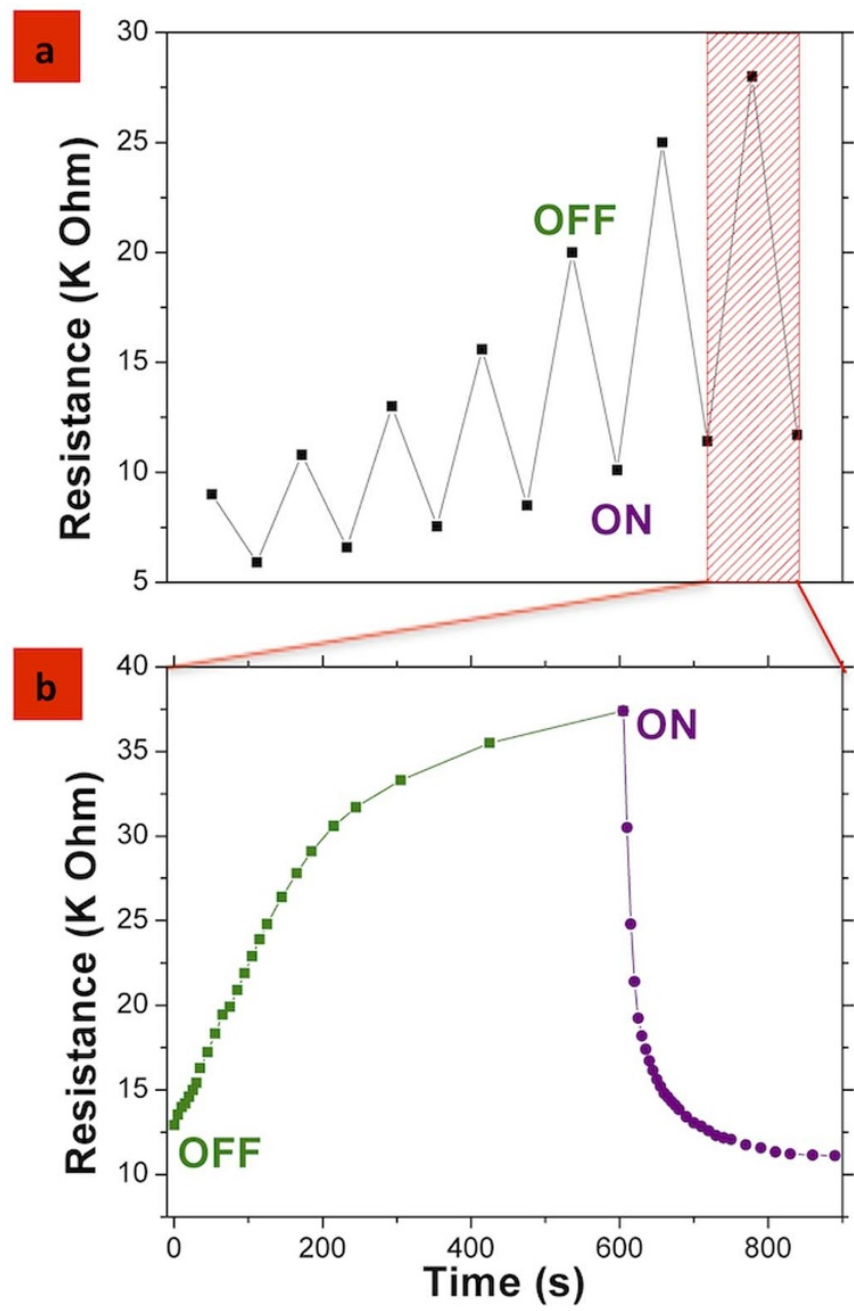

Figure $4 \mid \mathrm{HNO}_{3}$ gas sensing using $600^{\circ} \mathrm{C}$ annealed kaolin-GO nanocomposite. (a) Resistance of kaolin-GO films upon the blow of $\mathrm{HNO}_{3}$. (b) In-situ monitoring of resistance change of one cycle gas blowing marked with a light shaded rectangle in a.

gen gas. Such results are consistent with the results discussed by Levesque and co-workers ${ }^{26}$, where a substrate with a sensitive functional coating could minimize the background response to water. Our results clearly show that water molecules did not influence the conductance of the nanocomposite film, demonstrating that the electrical response was due to the $\mathrm{NH}_{3}$ molecules. However, as discussed above the adsorb water could assist in the response of ammonia. This interpretation is also consistent with the slopes of the sensitivity increase when cycling of the gas flow was applied. The relative change in resistance per cycle was 0.0637 for the nanocomposites annealed at $600^{\circ} \mathrm{C}, 0.0632$ and 0.012 for the nanocomposites annealed at $400^{\circ} \mathrm{C}$ and $950^{\circ} \mathrm{C}$, while it was only 0.0054 for the GO annealed sample without kaolin (Fig. 3c). The annealing at $950^{\circ} \mathrm{C}$ removed the carboxylate groups from the graphene oxide sheets, leading to less binding sites for ammonia and thus lower sensitivity ${ }^{25}$.

In addition to $\mathrm{NH}_{3}$ gas, we also investigated the response of kaolinGO nanocomposite to $\mathrm{HNO}_{3}$ (Fig. 4) by blowing nitrogen gas into $\mathrm{HNO}_{3}$ and then to a kaolin-GO nanocomposite sample that was annealed at $600^{\circ} \mathrm{C}$. In contrast to the response from $\mathrm{NH}_{3}$ gas, the resistance of the nanocomposite decreased upon the blow of $\mathrm{HNO}_{3}$ (concentration: $4.4 \mu \mathrm{M}$ ). The response might not only be caused by the interaction of $\mathrm{HNO}_{3}$ with annealed $\mathrm{GO}$, but also due to the accumulation of $\mathrm{HNO}_{3}$ on the GO-GO interface ${ }^{28}$, which increases the conductance between GO sheets, resulting in reduced resistance.
Moreover, the water absorbed by kaolin helps the accumulation of $\mathrm{HNO}_{3}$, which might also contribute to the response, yet we do not have direct evidence. Still, the results suggest that the kaolin-GO nanocomposite could be a potential material to make $\mathrm{HNO}_{3}$ sensor.

\section{Conclusions}

In summary, we produced kaolin-GO nanocomposites using a simple one-step method, through the link of APTES. The nanocomposites become conductive after thermal reduction as observed by real-time resistance measurement that were consistent with DSC measurements at $230^{\circ} \mathrm{C}$. The potential application of these nanocomposites for gas sensing was investigated by measuring the resistance changes upon blowing with $\mathrm{NH}_{3}$ and $\mathrm{HNO}_{3}$ gas. The nanocomposites, annealed at $400^{\circ} \mathrm{C}$ and $600^{\circ} \mathrm{C}$, showed a high sensitivity to $\mathrm{NH}_{3}$, which was much higher than a control sample consisting of only annealed GO. It is likely that both the reduced GO and the kaolin contributed to the gas sensing response. Our results suggest that this thermally reduced kaolin-GO nanocomposite could be useful in applications that require a low-cost material with large conductive surface area and in particular in for simple gas sensors. However, the selectivity of this gas sensor needs to be studied in the future to show the performance of the sensor in multi-gas situations.

\section{Methods}

Materials. GO was synthesized using the modified ${ }^{29}$ Hummers method and then dispersed in double distilled water for use. Kaolin powder, APTES, and all other chemicals used were purchased from SIGMA.

Synthesis of kaolin-GO nanocomposites and annealing. $1.0 \mathrm{~g}$ kaolin powder was first dispersed in $200 \mathrm{ml}$ doubly distilled water by probe sonication $(80 \mathrm{~W})$ for 2 hours to separate the flakes. After that, $4 \mathrm{ml} \mathrm{APTES}$ was added into the suspension while stirring at $500 \mathrm{rpm}$ for $10 \mathrm{~min}$, followed by adding various amount of GO solution while stirring at $800 \mathrm{rpm}$ for $10 \mathrm{~min}$. The samples were collected by filtration and rinsed with double distilled water for three times to remove remaining APTES that were not binding to kaolin. After that, the collected sample was re-dispersed in $100 \mathrm{ml}$ double distilled water. The annealing of kaolin-GO nanocomposites at 230 and $250^{\circ} \mathrm{C}$ was done in an oven without gas protection. The annealing at higher temperature than above was performed in a tube furnace with the protection of flowing argon gas.

Characterizations. SEM microscopy was done using an EVO50 microscope (ZEISS) with SE1 mode. TEM was performed on a JEOL 2000FX (JEOL) microscope. FTIR characterization was done on a Nicolet 6700 spectrometer. DSC measurements were done using a DSC822 (METTLER TOLEDO) thermal analyzer.

Specific surface area measurement. The Brunauer-Emmett-Teller (BET) specific surface area test was performed on a Micromeritics model 2300 (Micromeritics) using nitrogen as absorbent.

Electrical measurements. To do sheet resistance measurement, $1.0 \mathrm{ml}$ kaolin-GO nanocomposite suspension was dropped on $1.5 \times 1.5 \mathrm{~cm}^{2}$ oxidized silicon wafer and dried at $80^{\circ} \mathrm{C}$ for 1 hour. IV measurements were performed on a micromanipulator 1800 wafer probe station (Micromanipulator), using two stainless wires as source and drain electrodes. To do real time monitoring of the decarboxylation, two lines of silver glue, separated by $1 \mathrm{~cm}$, were made on the nanocomposite film. Two copper wires were attached to the silver glue contacts and connected to a multimeter for resistance measurements.

Gas sensing. The samples for gas sensing experiment were made the same way as those for real time decarboxylation monitoring. To do tests, nitrogen gas was first injected into ammonia (25\%) or nitric acid solution, which was then blown over the samples. The output gas concentration was $10 \mu \mathrm{M}$ for $\mathrm{NH}_{3}$ and $4.4 \mu \mathrm{M}$ for $\mathrm{HNO}_{3}$.

1. Novoselov, K. et al. Electric Field Effect in Atomically Thin Carbon Films. Science 306, 666-669 (2004).

2. Geim, a. K. \& Novoselov, K. S. The rise of graphene. Nat. Mater. 6, 183-191 (2007).

3. Liu, Z., Robinson, J. T., Sun, X. \& Dai, H. PEGylated nanographene oxide for delivery of water-insoluble cancer drugs. J. Am. Chem. Soc. 130, 10876-10877 (2008).

4. Bao, Q. et al. Atomic-Layer Graphene as a Saturable Absorber for Ultrafast Pulsed Lasers. Adv. Funct. Mater. 19, 3077-3083 (2009).

5. Schedin, F. et al. Detection of individual gas molecules adsorbed on graphene. Nat. Mater. 6, 652-655 (2007). 
6. Leenaerts, O., Partoens, B. \& Peeters, F. Adsorption of $\mathrm{H}_{2} \mathrm{O}, \mathrm{NH}_{3}, \mathrm{CO}, \mathrm{NO}_{2}$, and NO on graphene: A first-principles study. Phys. Rev. B 77, 125416 (2008).

7. Robinson, J. T., Perkins, F. K., Snow, E. S., Wei, Z. \& Sheehan, P. E. Reduced graphene oxide molecular sensors. Nano Lett. 8, 3137-3140 (2008).

8. Li, X. et al. Highly conducting graphene sheets and Langmuir-Blodgett films. Nat. Nanotechnol. 3, 538-542 (2008).

9. Gao, J. et al. Environment-Friendly Method To Produce Graphene That Employs Vitamin C and Amino Acid. Chem. Mater. 22, 2213-2218 (2010).

10. Sabio, J. et al. Electrostatic interactions between graphene layers and their environment. Phys. Rev. B 77, 195409 (2008).

11. Stankovich, S. et al. Graphene-based composite materials. Nature 442, 282-286 (2006).

12. Paek, S.-M., Yoo, E. \& Honma, I. Enhanced cyclic performance and lithium storage capacity of $\mathrm{SnO}_{2}$ /graphene nanoporous electrodes with threedimensionally delaminated flexible structure. Nano Lett. 9, 72-75 (2009).

13. Wang, D. et al. Self-assembled $\mathrm{TiO}_{2}$-graphene hybrid nanostructures for enhanced Li-ion insertion. ACS Nano 3, 907-914 (2009).

14. Wang, X., Tabakman, S. M. \& Dai, H. Atomic layer deposition of metal oxides on pristine and functionalized graphene. J. Am. Chem. Soc. 130, 8152-8153 (2008).

15. Wang, D. et al. Ternary self-assembly of ordered metal oxide-graphene nanocomposites for electrochemical energy storage. ACS Nano 4, 1587-1595 (2010).

16. Li, J., Guo, S., Zhai, Y. \& Wang, E. Nafion-graphene nanocomposite film as enhanced sensing platform for ultrasensitive determination of cadmium. Electrochem. Commun. 11, 1085-1088 (2009).

17. Zhang, Q. et al. Fabrication of a biocompatible and conductive platform based on a single-stranded DNA/graphene nanocomposite for direct electrochemistry and electrocatalysis. Chem.-Eur. J. 16, 8133-8139 (2010).

18. Nethravathi, C., Viswanath, B., Shivakumara, C., Mahadevaiah, N. \& Rajamathi, $\mathrm{M}$. The production of smectite clay/graphene composites through delamination and co-stacking. Carbon 46, 1773-1781 (2008)

19. Nethravathi, C., Rajamathi, J. T., Ravishankar, N., Shivakumara, C. \& Rajamathi, M. Graphite oxide-intercalated anionic clay and its decomposition to grapheneinorganic material nanocomposites. Langmuir 24, 8240-8244 (2008).

20. Ruiz-García, C. et al. Graphene-Clay Based Nanomaterials for Clean Energy Storage. Sci. Adv. Mater. 6, 151-158 (2014)

21. Zhang, R., Hummelgård, M. \& Olin, H. Simple synthesis of clay-gold nanocomposites with tunable color. Langmuir 26, 5823-5828 (2010).

22. Acik, M. et al. Unusual infrared-absorption mechanism in thermally reduced graphene oxide. Nat. Mater. 9, 840-845 (2010).

23. Wei, D. et al. Synthesis of N-doped graphene by chemical vapor deposition and its electrical properties. Nano Lett. 9, 1752-1758 (2009).

24. Robinson, J. A., Snow, E. S., Badescu, S. C., Reinecke, T. L. \& Perkins, F. K. Role of defects in single-walled carbon nanotube chemical sensors. Nano Lett. 6 , 1747-1751 (2006)
25. Seredych, M. \& Bandosz, T. J. Mechanism of Ammonia Retention on Graphite Oxides: Role of Surface Chemistry and Structure. J. Phys. Chem. C 111, 15596-15604 (2007)

26. Levesque, P. L. et al. Probing charge transfer at surfaces using graphene transistors. Nano Lett. 11, 132-137 (2011).

27. Xu, K., Cao, P. \& Heath, J. R. Graphene visualizes the first water adlayers on mica at ambient conditions. Science 329, 1188-1191 (2010).

28. Bower, C., Kleinhammes, A., Wu, Y. \& Zhou, O. Intercalation and partial exfoliation of single-walled carbon nanotubes by nitric acid. Chem. Phys. Lett. 288, 481-486 (1998).

29. Kovtyukhova, N. I. et al. Layer-by-Layer Assembly of Ultrathin Composite Films from Micron-Sized Graphite Oxide Sheets and Polycations. Chem. Mater. 11 771-778 (1999).

\section{Acknowledgments}

We acknowledge support from the Sundsvall Community, Energimyndigheten, Länstyrelsen Västernorrland, KK foundation, and European Regional Development fund.

\section{Author contributions}

R.Y.Z. and H.O. conceived the idea. R.Y.Z. did the experiments. V.A., M.H., B.A., S.F. and M.A. contributed to the experiments. All authors discussed the results and contributed to the manuscript.

\section{Additional information}

Supplementary information accompanies this paper at http://www.nature.com/ scientificreports

Competing financial interests: The authors declare no competing financial interests.

How to cite this article: Zhang, R. et al. Thermally reduced kaolin-graphene oxide nanocomposites for gas sensing. Sci. Rep. 5, 7676; DOI:10.1038/srep07676 (2015).

This work is licensed under a Creative Commons Attribution-NonCommercialShareAlike 4.0 International License. The images or other third party material in this article are included in the article's Creative Commons license, unless indicated otherwise in the credit line; if the material is not included under the Creative Commons license, users will need to obtain permission from the license holder in order to reproduce the material. To view a copy of this license, visit http:// creativecommons.org/licenses/by-nc-sa/4.0/ 